\title{
Schauinsland Ozone Precursor Experiment (SLOPE96): Scientific background and main results
}

\author{
Andreas Volz-Thomas and Heiner Geiß \\ Institut für Chemie und Dynamik der Geosphäre II, Forschungszentrum Jülich, Jülich, Germany \\ Norbert Kalthoff \\ Institut fur Meteorologie und Klimaforschung, Forschungszentrum Karlsruhe, Karlsruhe, Germany
}

\begin{abstract}
The Schauinsland Ozone Precursor Experiment (SLOPE) was conducted in June 1996 as part of the former European Experiment on Transport and Transformation of Environmentally Relevant Trace Constituents in the Troposphere Over Europe (EUROTRAC) subproject Tropospheric Ozone Research (TOR) in order to study the photochemical formation of ozone and the degradation of the precursors in the plume of the city of Freiburg on its way to Schauinsland. Chemical and meteorological measurements were made at several surface sites in a valley that channels the airflow to Schauinsland, including vertical profiles at several locations, and aboard a small aircraft. A tracer experiment with $\mathrm{SF}_{6}$ was made in order to establish transport and dispersion in the valley. Particular emphasis was on the determination of the $\mathrm{OH}$ concentration from the decay of hydrocarbons during transport. The relatively high $\mathrm{OH}$ concentration of $7 \times 10^{6}$ $\mathrm{cm}^{-3}$ in the presence of high $\mathrm{NO}_{x}$ concentrations $(3-15 \mathrm{ppb})$ indicates the potential for unidentified processes in the $\mathrm{HO}_{x}$ budget in the high- $\mathrm{NO}_{x}$ regime which may have important consequences for the ozone budget and smog chemistry in the urban/suburban environment.
\end{abstract}

\section{Introduction}

The transition region between urban and rural areas is important in understanding the fast photochemistry that leads to the buildup of high concentrations of ozone and other photooxidants during so-called summer smog episodes. While several experiments have investigated the budgets of ozone and radicals at low and moderate $\mathrm{NO}_{x}$ concentrations, including direct spectroscopic measurements of [OH] [e.g., Dorn et al., 1988; Eisele et al., 1994; Mount and Williams, 1997; Holland et al., 1998], little quantitative experimental information exists so far on the ozone balance and the radical concentrations in the high $\mathrm{NO}_{x}$ regime.

The $\mathrm{OH}$ concentration and the production rate of ozone both depend in a nonlinear fashion on the UV flux and on the concentrations of $\mathrm{NO}_{x}$ and VOCs. The role of $\mathrm{NO}_{x}$ in the budgets of $\mathrm{HO}_{x}\left(\left[\mathrm{HO}_{x}\right]=[\mathrm{OH}]+\left[\mathrm{HO}_{2}\right]\right)$ and ozone is ambivalent. At low $\mathrm{NO}_{x}$ concentrations, where recombination of the peroxy radicals constitutes the major radical loss, [NO] controls the recycling of $\mathrm{OH}$ and is the rate-limiting factor in ozone production [Logan et al., 1981; Crutzen, 1979]. At high $\mathrm{NO}_{x}$ levels, on the other hand, radical losses by recombination of peroxy radicals become insignificant, and $\mathrm{HO}_{2}$ is almost completely recycled to $\mathrm{OH}$. In the presence of sufficient $\mathrm{NO}$, even more radicals can be produced from the hydrocarbon oxidation mechanism than initially consumed, because of the photolysis of the carbonyl compounds formed in the mechanism [Jeffries and Tonnesen, 1994; Jang et al., 1995]. This effect is counteracted by the reaction of $\mathrm{OH}$ with $\mathrm{NO}_{2}$, which becomes the predominant sink of $\mathrm{HO}_{x}$ in the high- $\mathrm{NO}_{x}$ regime

Copyright 2000 by the American Geophysical Union.

Paper number 1999JD900919.

0148-0227/00/1999JD900919\$09.00 and thus limits the production of $\mathrm{RO}_{2}$ and $\mathrm{HO}_{2}$. The net effect of $\mathrm{NO}_{x}$ on the radical balance and ozone formation depends on the $\mathrm{NO} / \mathrm{NO}_{2}$ ratio, which is controlled by the UV radiation flux $\left(J_{\mathrm{NO}_{2}}\right)$ and by the concentrations of peroxy radicals and $\mathrm{O}_{3}$. The radical chemistry in the high- $\mathrm{NO}_{x}$ regime is further complicated by the fact that photolysis of nitrous acid (HONO), which is coemitted with $\mathrm{NO}_{x}$ [Kessler and Platt, 1984] and/or produced from $\mathrm{NO}_{x}$ via heterogeneous reactions [cf. Harrison et al., 1996], is a potentially important source of $\mathrm{HO}_{x}$ in polluted air, in particular during the morning hours.

In addition to chemistry, the local concentration of trace gases is influenced by transport, dispersion, and deposition. Which of the different processes dominates depends on the chemical lifetime of the species and on the meteorological conditions. While the concentrations of $\mathrm{OH}$ and other shortlived radicals are reasonably well described by the local chemical fields, transport usually dominates the local rate of change of the longer-lived trace gases such as ozone. For example, the daily ozone maximum which develops under fair weather conditions results by approximately $70 \%$ from downward mixing of ozone from the residual layer to the surface layer, while only the remaining $30 \%$ can be related to local chemical formation [Fiedler, 1998]. Therefore information about the meteorological conditions like mixing layer height, stratification of the boundary layer, and three-dimensional structure of the wind field is essential for the determination of the contributions of advection and diffusion in an experiment that aims at the budgets of trace gases. This is particularly the case in complex terrain, where thermally induced periodic wind systems [Atkinson, 1981; Whiteman, 1990; Barry, 1992], like slope and valley winds, are important for the ventilation of the valley atmosphere and have a strong influence on the local change of trace gases [e.g., Carroll and Baskett, 1979; Kurita et al., 1990; Millan, 
1992; Bischoff-Gauß et al., 1998]. In order to separate the contributions of transport and dispersion on the local concentration changes from the chemical transformation processes it is advantageous to analyze the behavior of an artificial inert tracer, in addition to measurements of the chemical composition of the air [e.g., Wilson et al., 1983; Clements et al., 1989; Allwine, 1993].

With this in mind, and on the basis of earlier experiments, the following strategy was selected for the Schauinsland Ozone Precursor Experiment (SLOPE96). The steep and narrow valley "Großes Tal" between the city of Freiburg and the Schauinsland observatory was used as approximation of a flow reactor to study the chemical and physical development of the city plume of Freiburg in a quasi-Lagrangian approach by detailed meteorological and chemical measurements, including a tracer experiment with $\mathrm{SF}_{6}$. The advantage of using a valley for such an experiment is the well-defined transport path, which makes it relatively easy to arrange the measurement systems, and that the exchange of the transported air mass with the surrounding environment is restricted to the vertical dimension. A particular advantage of the Großes Tal for a chemical budget study is its very thin population and the absence of a transit road.

The details of the various measurements and the scientific results are described in subsequent manuscripts of the special section. This paper briefly outlines the history and the layout of SLOPE96 and summarizes the main results and conclusions.

\section{History of SLOPE}

The field station Schauinsland $\left(47^{\circ} 54^{\prime} \mathrm{N}, 7^{\circ} 48^{\prime} \mathrm{E} ; 1230 \mathrm{~m}\right.$ above sea level (asl) [Volz-Thomas et al., 1997]) was operated between 1989 and 1996 as part of the European Experiment on Transport and Transformation of Environmentally Relevant Trace Constituents in the Troposphere Over Europe (EUROTRAC) subproject Tropospheric Ozone Research (TOR) [Kley et al., 1997]. It is located in the southern part of the Black Forest mountains (Figure 1) on a saddle about $400 \mathrm{~m}$ east of the Schauinsland summit $(1284 \mathrm{~m}$ asl). The area around the station is characterized by a general decline within about $10 \mathrm{~km}$ to the Rhine Valley in the west $(250 \mathrm{~m}$ asl). The hills and valleys south, west, and northwest of the station are mostly covered with coniferous and deciduous forest. The remaining parts are covered with grasslands, interrupted by small tree and bush stands. The site is shielded from direct influence of local traffic by a ridge. The road to the observatory is closed for public traffic for the last $1.5 \mathrm{~km}$. The nearest settlement (some 100 inhabitants) is about $2 \mathrm{~km}$ away, and the next major city is Freiburg (120,000 inhabitants) in the Rhine Valley, about 11 $\mathrm{km}$ northwest. Toward northwest the terrain declines with a slope of more than $20 \%$ into the narrow valley Großes Tal, in which the SLOPE experiment took place.

Figure 2 shows the summertime wind roses for Schauinsland and for Feldberg, the highest mountain of the Black Forest (1486 $\mathrm{m}$ asl, about $10 \mathrm{~km}$ southeast of Schauinsland). Although not truly representative of the geostrophic flow, Feldberg is not much influenced by local topography and thus should be representative of the wind field in the upper planetary boundary layer (PBL) in the region, whereas the wind field at the TOR station Schauinsland is strongly influenced by local topography and the vicinity of the Rhine Valley.

While the wind rose of Feldberg shows the expected maximum at southwesterlies $\left(35.6 \%\right.$ between $230^{\circ}$ and $\left.190^{\circ}\right)$ with secondary maxima in the northeast, the southwesterly compo- nent is much less pronounced at Schauinsland, and the northeasterly components are completely absent. Instead, there is a strong peak at northwesterly winds ( $>40 \%$ during daytime), which is due to the up-valley wind system in the Großes Tal. The northwest wind is, in general, associated with low wind speeds $\left(90 \%<3 \mathrm{~m} \mathrm{~s}^{-1}\right)$. At night, southeasterly wind directions are more frequent, and the northwesterly component is strongly reduced. In winter (not shown), northwesterly winds are rather seldom, mostly during frontal passages, and there is almost no difference between day and night.

The chemical situation is illustrated by the average diurnal variations of the trace gases in summer in Figure 3. Schauinsland is exposed to very clean air from southwesterly directions. The next larger agglomeration in that direction is Lyon, about $300 \mathrm{~km}$ away. The data from the northwest sector show a pronounced diurnal cycle, which is due to the fact that Schauinsland usually resides above the inversion at night. The peak at noon is caused by the breakup of the inversion in the morning and the establishment of the valley wind system in the Großes Tal. The pronounced diurnal variation in the northwest sector is a clear indication for the Rhine Valley being a strong source for pollutants and photooxidants at Schauinsland. As is exhibited by the $\mathrm{NO}_{x}$ and $\mathrm{NO}_{y}$ data in Figure 3, these air masses have been subjected to relatively fresh emissions, for example, from the Rhine Valley and the city of Freiburg, leading to fairly large concentrations of ozone in the course of the day.

The regular appearance of the northwesterly winds at Schauinsland led to the idea of utilizing the valley Großes Tal as an approximation of a flow reactor. A first experiment was conducted in September 1992 with ground-based measurements made in Kappel, a small village at the entrance of the valley, and at Schauinsland (see Figure 4). Both sites were equipped with instrumentation for $\mathrm{NO}, \mathrm{NO}_{x}, \mathrm{NO}_{y}, \mathrm{O}_{3}, J_{\mathrm{NO}_{2}}$, and $\mathrm{C}_{2}-\mathrm{C}_{8}$ hydrocarbons and meteorological parameters [Kramp and Volz-Thomas, 1997].

Similar to the approaches used by, for example, Calvert [1976], Roberts et al. [1984], Satsumabayashi et al. [1992], Blake et al. [1993], Jobson et al. [1994], and McKenna et al. [1995], the $\mathrm{OH}$ concentration was estimated by simultaneously integrating the continuity equation (1) for a family of reactive hydrocarbons $\mathrm{RH}_{\imath}$,

$$
\frac{\partial\left[\mathrm{RH}_{t}\right]}{\partial t}=P_{\mathrm{RH}_{t}}-L_{\mathrm{RH}_{t}}-\mathbf{u} \nabla\left[\mathrm{RH}_{t}\right]-\nabla\left(K \nabla\left[\mathrm{RH}_{t}\right]\right)
$$

where $\partial / \partial t$ is the local rate of change, $P$ and $L$ are the local production and loss terms, and $\mathbf{u} \nabla\left[\mathrm{RH}_{t}\right]$ and $\nabla\left[K \nabla\left[\mathrm{RH}_{t}\right]\right)$ is the flux divergence due to advection and turbulence.

As has been discussed in several publications [McKeen and Liu, 1993; McKenna, 1997; Kramp and Volz-Thomas, 1997; Ehhalt et al., 1998], the successful application of the so-called hydrocarbon clock relies on the fulfillment of several assumptions: First of all, it is assumed that the reaction with OH (R1) constitutes the major chemical loss process for the hydrocarbons considered.

$$
\mathrm{RH}+\mathrm{OH}+\mathrm{O}_{2} \rightarrow \mathrm{RO}_{2}
$$

In this sense, it must be emphasized that the result does not constitute a positive identification of $\mathrm{OH}$ in the atmosphere but rather relies on the wisdom about the role of $\mathrm{OH}$ as the major oxidant in the sunlit atmosphere [Levy, 1971]. The chemical losses are then given by 


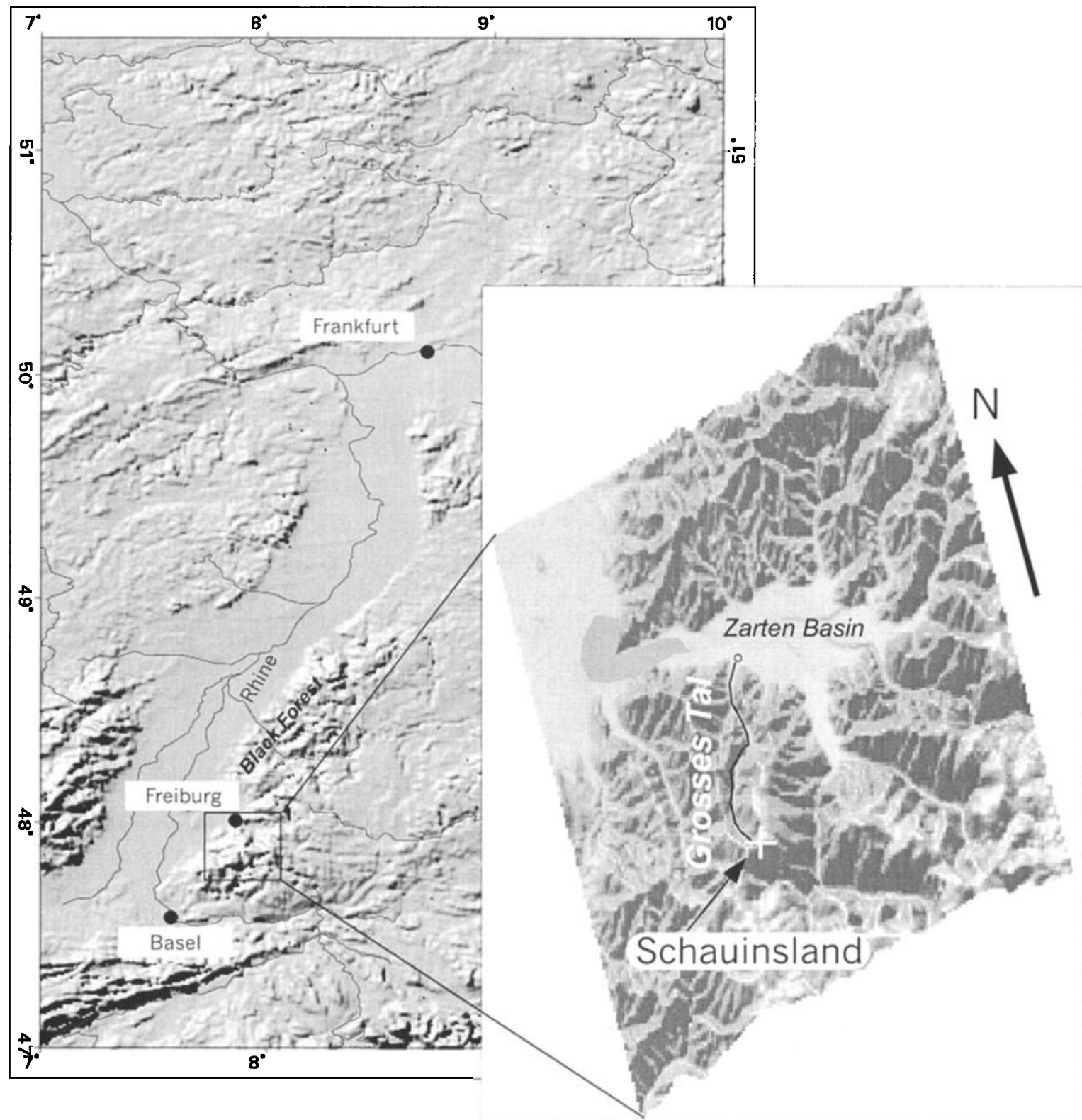

Figure 1. Map of the Upper Rhine Valley and the Black Forest mountains with the location of Schauinsland and the city of Freiburg. The insert gives an enlarged view of the area around Freiburg and the Zarten Basin, with the Großes Tal marked by the solid line.

$$
L_{\mathrm{RH}_{t}}=\left[\mathrm{RH}_{t}\right] \times[\mathrm{OH}] \times k_{1 t}
$$

with $k_{1 i}$ being the rate coefficients for (R1), which must be known from laboratory measurements. Second, chemical production and emissions of the considered hydrocarbons during transport between the two measurements must be negligible. Last but not least, (1) can only be integrated if the dilution term is equal for all hydrocarbons, such that the term $\nabla\left(K \nabla\left[\mathrm{RH}_{i}\right]\right)$ can be approximated by a first-order loss process with a dilution coefficient $k_{d}$. With these assumptions and after transformation into Lagrangian coordinates, we obtain

$$
-\frac{d\left[\mathrm{RH}_{t}\right]}{d t}=\left[\mathrm{RH}_{t}\right] \times\left([\mathrm{OH}] \times k_{1 t}+k_{d}\right)
$$

and after integration,

$$
\begin{aligned}
& \ln \left(\left[\mathrm{RH}_{t}\right]_{t_{2}}\left[\left[\mathrm{RH}_{t}\right]_{t_{1}}\right)=-\int_{\Delta t}[\mathrm{OH}] \times k_{1 i} d t-\int_{\Delta t} k_{d} d t\right. \\
& \approx-[\overline{\mathrm{OH}}] \times k_{1 i} \times \Delta t-\bar{k}_{d} \times \Delta t
\end{aligned}
$$

According to (3) the average $\mathrm{OH}$ concentration can be estimated from the slope of a semilogarithmic plot of the ratios of the individual hydrocarbons versus the respective rate coefficients $\left(k_{1 z}\right)$ with $\mathrm{OH}$. The ratios $\left[\mathrm{RH}_{i}\right]_{t_{2}} /\left[\mathrm{RH}_{i}\right]_{t_{1}}$ are formed from concentration pairs that are measured at Kappel at the time $t_{1}$ and at Schauinsland at the time $t_{2}$. Precondition for 


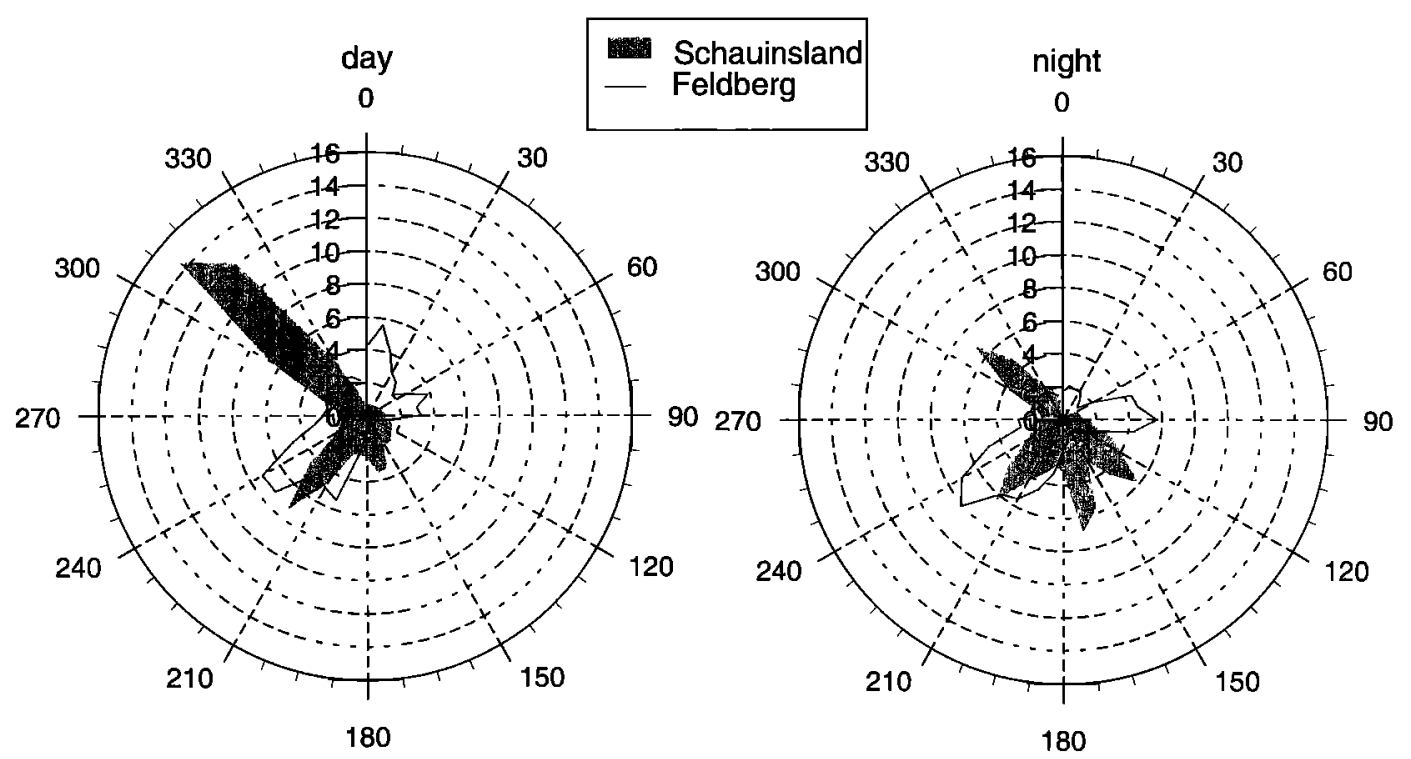

Figure 2. Wind rose at Schauinsland and Feldberg during summer: (left) day and (right) night.

determination of the $\mathrm{OH}$ concentration from the slope is the knowledge of the transport time $\Delta t=t_{2}-t_{1}$ between the two points of measurement. The first-order dilution term, which is equivalent to a volumetric dilution factor $\left(k_{d} \Delta t=\ln \left(V_{t} /\right.\right.$ $\left.V_{t_{2}}\right)$ ), is derived from the intercept with the ordinate. In 1992 the transport time was estimated from the local wind speed at

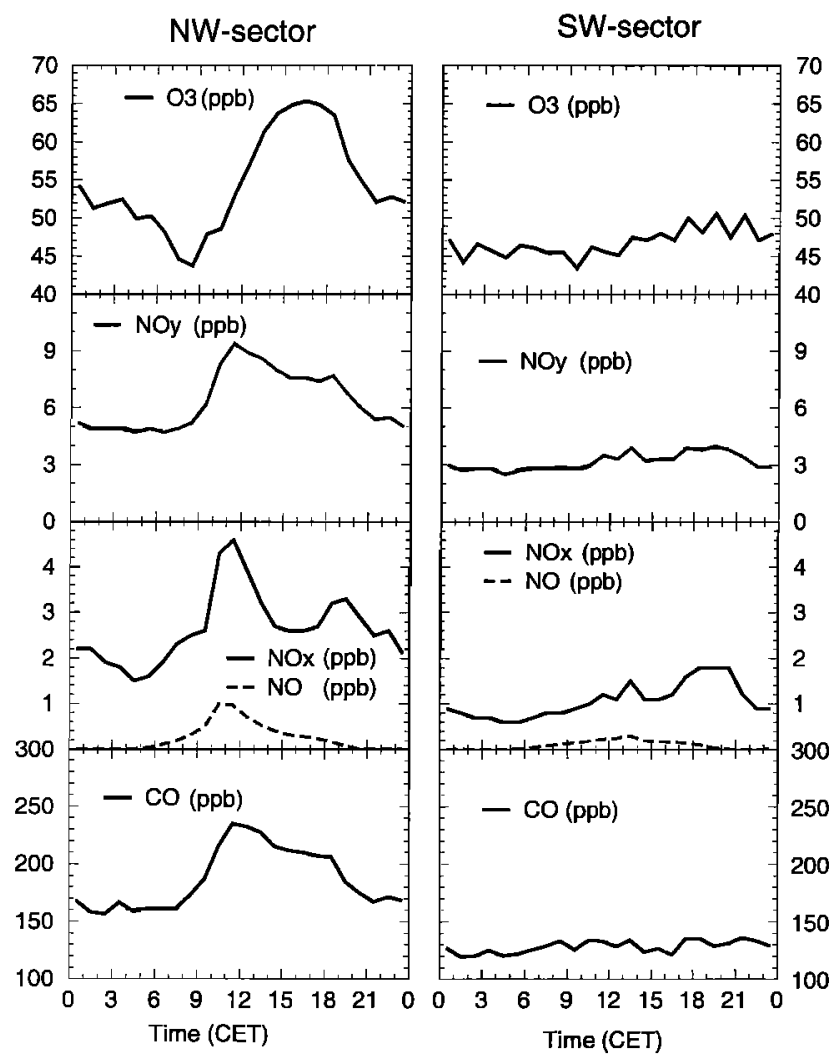

Figure 3. Average diurnal variation of $\mathrm{O}_{3}, \mathrm{NO}_{y}, \mathrm{NO}_{x}$, and $\mathrm{CO}$ in summer for the two main wind sectors observed at Schauinsland.
Kappel and Schauinsland and by minimizing the overall variance in the semilogarithmic regressions made for all sets $\left[\mathrm{RH}_{t}\right]_{t 1+\Delta t} /\left[\mathrm{RH}_{i}\right]_{t 1}$ in the time interval when the valley wind system persisted [Kramp and Volz-Thomas, 1997].

In view of the large $\mathrm{NO}_{x}$ mixing ratio in the investigated air mass (70 ppb at Kappel and 15 ppb at Schauinsland), the $\mathrm{OH}$ concentration (5-8 $\times 10^{6}$ molecules $\mathrm{cm}^{-3}$ ) obtained from the hydrocarbon decay was surprisingly large. An analysis of the radical budget showed that the large $\mathrm{OH}$ was not sustained by the primary sources, even when including an estimate for HONO photolysis. As a possible explanation, it was postulated that amplification processes during the oxidation of hydrocarbons may lead to the production of more $\mathrm{HO}_{x}$ radicals (in the form of $\mathrm{HO}_{2}$ ) than originally consumed in the reaction of the hydrocarbons with $\mathrm{OH}$. In order to close the budget it was calculated that on the basis of the measured hydrocarbons 2 $\mathrm{HO}_{2}$ radicals had to be formed in the course of the degradation of an initial $\mathrm{RO}_{2}$ radical. Such a large amplification factor seemed unreasonable, and it was argued that biogenic VOCs other than isoprene, which were not measured in 1992, might have contributed to the $\mathrm{HO}_{x}$ recycling and radical amplification, in addition to the radical production from the ozonolysis of olefinic VOCs, for example, terpenes.

Uncertainties in the 1992 experiment were associated with the assumptions about the general transport path, the transport time, and the influence of mixing processes, in particular after total development of the boundary layer. In order to reduce these uncertainties, tracer experiments with $\mathrm{SF}_{6}$ were conducted in the following years. The result of the preexperiments confirmed the assumption that the transport of polluted air from Freiburg to Schauinsland indeed proceeded through the valley Großes Tal. Transport time and dilution factor were found to be similar to those derived from the experiment in 1992.

On the basis of these encouraging results, SLOPE96 was planned and conducted in June 1996 with two intensive measuring campaigns (June 4-6 and 27). The different research groups and measurement systems that participated in the campaign are listed in Table 1 , and Figure 4 gives a three- 


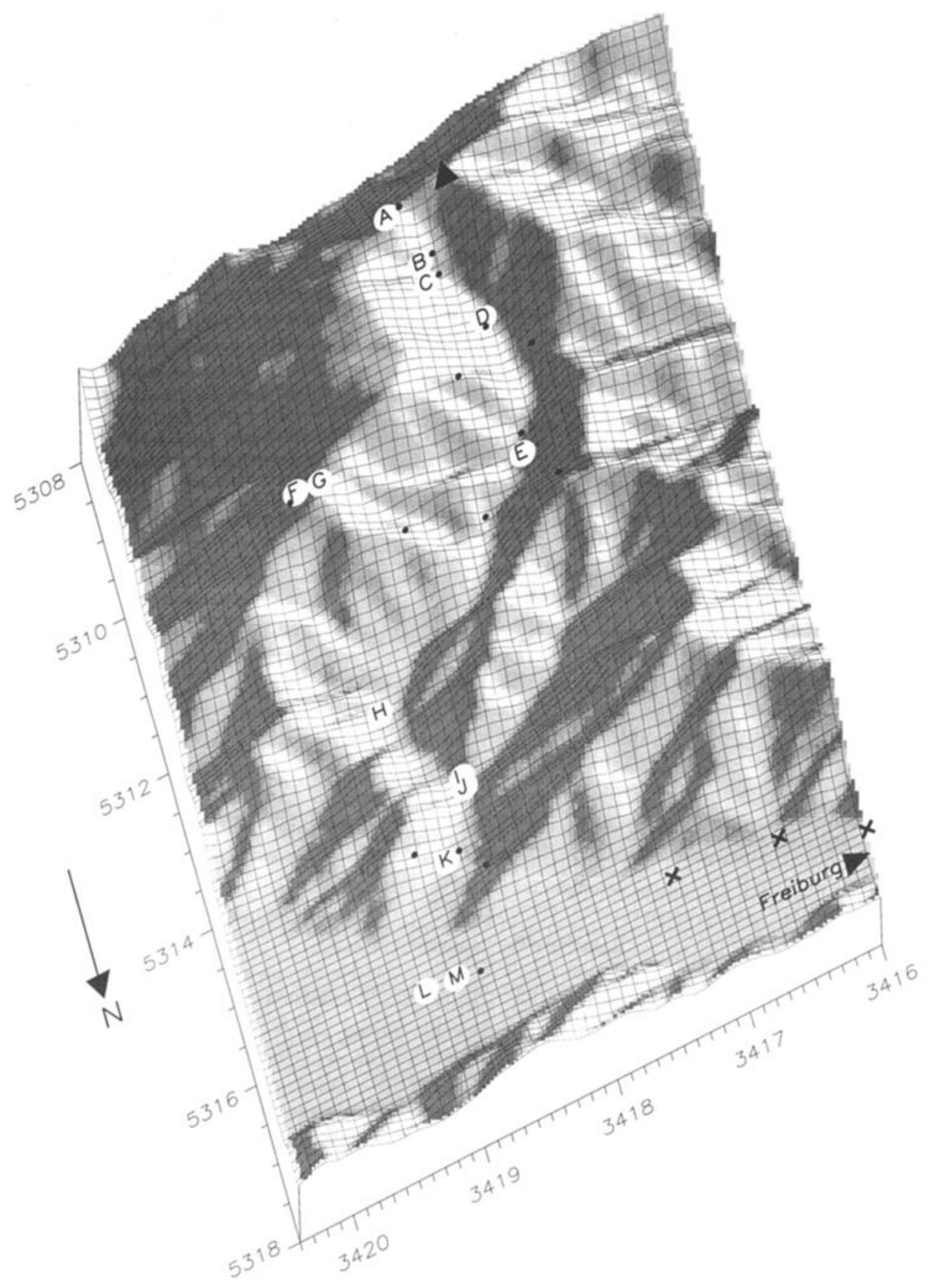

Figure 4. Three-dimensional map of the Großes Tal and parts of the Zarten Basin with the measurement sites during SLOPE96 (for explanation of the sites, see Table 1).

dimensional view of the valley with the measurement sites. Detailed ground-based chemical measurements were made at Kappel and Schauinsland. A relatively dense meteorological surface network was installed to analyze the development of the valley wind systems in the different valleys. Vertical profiles of ozone, $\mathrm{NO}_{2}$, and meteorological parameters were obtained with remote sensing techniques (four SODARs and two ozone LIDARs) and from three tethered balloons. Airborne measurements of hydrocarbons, ozone, $\mathrm{NO}_{2}$, and meteorological data were made aboard a small airplane. An inert tracer $\left(\mathrm{SF}_{6}\right)$ was released into the city plume of Freiburg to obtain quantitative information on advection and dispersion, and model calculations were carried out to support the interpretation of the meteorological phenomena and the behavior of the tracer. The analysis concentrated on the data from June 5, 1996, when clear air conditions led to the development of necessary upvalley winds, a prerequisite for the transport path from Freiburg via the Großes Tal to Schauinsland.

\section{Summary of the Publications on SLOPE96}

B. Kolahgar et al. (unpublished manuscript, 1999) describe the experimental methods used for determination of VOCs at the two surface sites and aboard the small aircraft. At each site 
Table 1. Participants in SLOPE96 and Description of the Measurements Sites Shown in Figure 4

\begin{tabular}{|c|c|c|c|c|}
\hline $\begin{array}{c}\text { Symbol } \\
\text { (Figure 4) }\end{array}$ & $\begin{array}{l}\text { Height, } \\
\text { m asl }\end{array}$ & Measuring System & Institution & Acronym \\
\hline A & 1230 & $\begin{array}{l}\text { TOR station Schauinsland } \\
\text { (chemistry, meteorology) }\end{array}$ & $\begin{array}{l}\text { Forschungszentrum Jülich-Institut fur Chemie } \\
\text { und Dynamik der Geosphäre (ICG2) }\end{array}$ & ICG2 \\
\hline $\mathbf{B}$ & 1060 & meteorological tower & Uni Paderborn & UPB \\
\hline $\mathrm{F}$ & 980 & SODAR & $\begin{array}{l}\text { Forschungszentrum Karlsruhe-Institut für } \\
\text { Meteorologie und Klimaforschung }\end{array}$ & IMK \\
\hline $\mathbf{G}$ & 995 & meteorological tower & Uni Freiburg Geologisches Institut & MIF \\
\hline $\mathrm{C}$ & 980 & meteorological tower & Uni Paderborn & UPB \\
\hline D & 830 & ozone-LIDAR, SODAR & Forschungszentrum Geesthacht & GKSS \\
\hline $\mathrm{D}$ & 830 & $\begin{array}{l}\text { tethered balloon }\left(\mathrm{O}_{3}\right. \\
\text { meteorology) }\end{array}$ & $\begin{array}{l}\text { Forschungszentrum Karlsruhe-Institut für } \\
\text { Meteorologie und Klimaforschung }\end{array}$ & IMK \\
\hline $\mathrm{E}$ & 630 & IFU measuring container & $\begin{array}{l}\text { Fraunhoferinstitut fur Atmosphärische } \\
\text { Umweltforschung }\end{array}$ & IFU \\
\hline $\mathbf{H}$ & 495 & $\begin{array}{l}\text { tethered balloon } \\
\text { (meteorology) }\end{array}$ & Uni Freiburg Geologisches Institut & MIF \\
\hline $\mathbf{I}$ & 392 & $\begin{array}{l}\text { launch site for Zeppelin }\left(\mathrm{O}_{3} \text {, }\right. \\
\text { meteorology) }\end{array}$ & $\begin{array}{l}\text { Uni Stuttgart-Institut für Statik und Dynamik } \\
\text { der Luft- und Raumfahrt }\end{array}$ & IVD \\
\hline $\mathbf{J}$ & 385 & $\begin{array}{l}\text { tethered balloon }\left(\mathrm{O}_{3}, \mathrm{NO}_{2} \text {, }\right. \\
\text { meteorology) }\end{array}$ & $\begin{array}{l}\text { Uni Stuttgart-Institut für Verfahrenstechnik } \\
\text { und Dampfkesselwesen }\end{array}$ & IVD \\
\hline $\mathrm{K}$ & 354 & $\begin{array}{l}\text { mobile laboratory (chemistry, } \\
\text { meteorology) }\end{array}$ & Forschungszentrum Julich-ICG2 & ICG2 \\
\hline $\mathrm{K}$ & & meteorological tower, SODAR & $\begin{array}{l}\text { Forschungszentrum Jülich-ASS, Universitàt } \\
\text { Köln, Meteorologisches Institut }\end{array}$ & $\begin{array}{l}\text { ASS } \\
\text { MIK }\end{array}$ \\
\hline $\mathbf{K}$ & & ozone-LIDAR & Max-Planck-Institut Hamburg & MPI \\
\hline $\mathrm{L}$ & 330 & SODAR & Uni Freiburg Geologisches Institut & MIF \\
\hline $\bar{M}$ & 327 & radio sonde & $\begin{array}{l}\text { Forschungszentrum Karlsruhe-Institut für } \\
\text { Meteorologie und Klimaforschung }\end{array}$ & IMK \\
\hline $\mathbf{X}$ & 327 & $\mathrm{SF}_{6}$ release sites & Forschungszentrum Jülich—ASS & ASS \\
\hline - & & $\mathrm{SF}_{6}$-sampling sites & Forschungszentrum Jülich—ASS & ASS \\
\hline
\end{tabular}

a self-built gas chromatographic (GC) system with cryogenic preconcentration was operated in combination with a commercial GC (Airmotec HC1010) that achieves a better time resolution ( $20 \mathrm{~min}$ ) but suffers from coelution and memory effects for some compounds. Another Airmotec GC was operated aboard the aircraft (time resolution $10 \mathrm{~min}$ ). Measurements of $\left(\mathrm{C}_{8}-\mathrm{C}_{15}\right)$ VOCs were made at the surface sites by GC-MS on samples collected on charcoal adsorption tubes. The data quality was explored on the basis of an instrument comparison using calibration standards and concurrent measurements in ambient air. Particular emphasis of the comparison was to identify those compounds that were measured by the three Airmotec instruments with a comparability of better than $10 \%$ to be used for the determination of $\mathrm{OH}$.

The measurements of all systems were combined in order to obtain an estimate of the total VOC reactivity and the VOC/ $\mathrm{NO}_{x}$ ratio. During the time when the city plume of Freiburg was transported through the Großes Tal, about $50 \%$ of the VOC reactivity was due to biogenic VOCs. The latter included a relatively large fraction from terpenes and from oxygenated compounds.

Pätz et al. [this issue] discuss the ground-based measurements of inorganic compounds and photolysis rates, and the chemical measurements made on the tethered balloons and aboard the aircraft. Again, an instrument comparison was conducted which was used for harmonization of the data sets for ozone and nitrogen oxides. Additional checks were made using situations in which the aircraft was in the vicinity of the Schauinsland station and of the tethered balloon.

From the measurements of $\mathrm{NO}, \mathrm{NO}_{2}, \mathrm{NO}_{y}, \mathrm{PAN}$, and $\mathrm{HNO}_{3}$ at Schauinsland, an estimate of the noontime $\mathrm{OH}$ concentration of $1 \times 10^{7} \mathrm{~cm}^{-3}$ is derived with a simple quasi steady state model. The temporal behavior of the different
$\mathrm{NO}_{y}$ compounds is well predicted by the steady state model when dry deposition for $\mathrm{HNO}_{3}$ is included with a first-order loss term corresponding to a deposition velocity of $2-3 \mathrm{~cm} \mathrm{~s}^{-1}$. The local ozone production rate as estimated at Schauinsland from the photostationary state of $\mathrm{NO}_{x}$ shows a positive correlation with the product of UV radiation $\left(J_{\mathrm{NO}_{2}}\right)$ and precursor concentrations $\left(\mathrm{NO}_{x}\right)$ with maximum values around $60 \mathrm{ppb}$ $\mathrm{h}^{-1}$.

M. Möllmann-Coers et al. (unpublished manuscript, 1999) describe the planning and conduction of the tracer experiment. The optimum release sites were found in preexperiments conducted between 1993 and 1995 and with the aid of model simulations with the Karlsruhe Atmospheric Mesoscale Model (KAMM) [Fiedler, 1993]. From simultaneous $\mathrm{SF}_{6}$ and $\mathrm{CO}$ measurements made in the samples it is concluded that anthropogenic emissions in the Großes Tal are of negligible importance for the concentrations in the city plume of Freiburg.

Kalthoff et al. [this issue] discuss the results of the meteorological measurements and the tracer experiment. The data from meteorological surface sites and vertical soundings are used to analyze the temporal development of the valley wind system and the mixed layer height within the different valleys. The data show that from 0900 to 1200 central European time (CET) up-valley wind systems existed in the Großes Tal and in the Zarten Basin, leading to the transport of polluted air from Freiburg via the Zarten Basin and the Großes Tal to the Schauinsland mountain. Around midday, however, a largerscale westerly flow above the Black Forest hills disturbed the up-valley wind system in the Großes Tal. This was of relevance for the interpretation of the temporal behavior of $\mathrm{SF}_{6}$ and $\mathrm{NO}_{x}$ at Schauinsland.

From the tracer, $\mathrm{SF}_{6}$, which was released between 0900 and $1030 \mathrm{CET}$ at three sites in the Zarten Basin, the transport time 

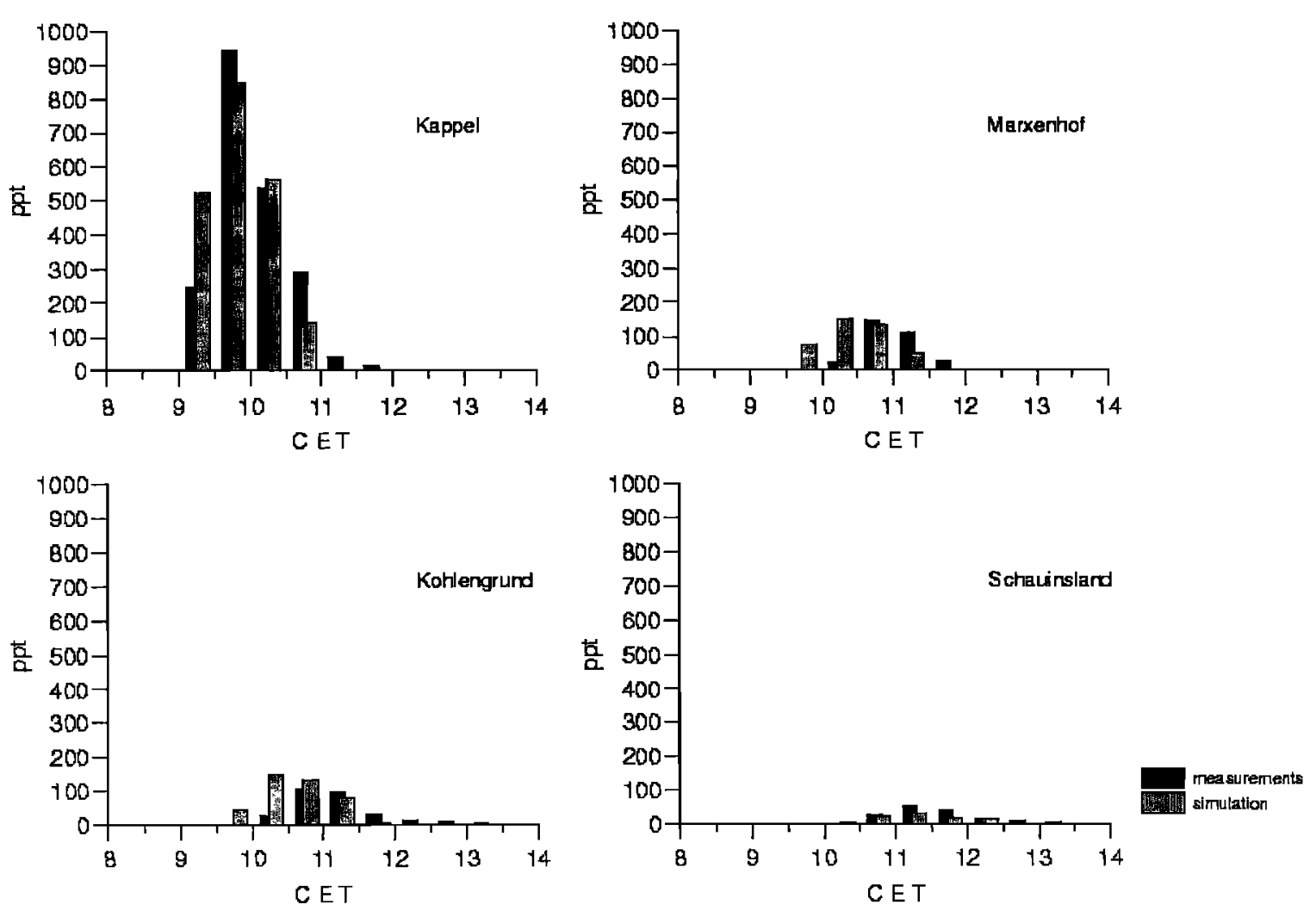

Figure 5. Comparison of the measured $\mathrm{SF}_{6}$ concentrations in the Großes Tal with the model simulations (Marxenhof: site E, Kohlengrund: site D) [Fiedler et al., this issue].

and dilution rate was calculated (Figure 5). At the entrance of the Großes Tal the peak of $942 \mathrm{ppt}$ appeared between 0930 and $1000 \mathrm{CET}$. At Schauinsland the $\mathrm{SF}_{6}$ peak of $79 \mathrm{ppt}$ was detected between 1100 and 1130 CET. The transport time between Kappel and Schauinsland as derived by fitting a modified Gauss function to the observed $\mathrm{SF}_{6}$ concentrations was $90 \pm 5 \mathrm{~min}$, corresponding to a propagation rate of $1.5 \mathrm{~m} \mathrm{~s}^{-1}$. The $\mathrm{SF}_{6}$ concentration was reduced during transport between the two sites by approximately a factor of 10 .

The $\mathrm{NO}_{x}$ peak appeared between 0900 and $1030 \mathrm{CET}$ at the entrance of the Großes Tal in coincidence with the $\mathrm{SF}_{6}$ peak. At Schauinsland, however, the $\mathrm{NO}_{x}$ data revealed two peaks. A first but minor peak was detected before $1200 \mathrm{CET}$, together with the $\mathrm{SF}_{6}$ peak. The major $\mathrm{NO}_{x}$ peak appeared much later at about 1300 CET. This was caused by the change in wind direction at $1200 \mathrm{CET}$, which led to advection of polluted air from the Rhine Valley. For this reason, only the data before $1200 \mathrm{CET}$ could be used for calculation of $\mathrm{OH}$ concentrations from the hydrocarbon decay during transport in the Großes Tal.

Fiedler et al. [this issue] present model calculations, which support the observed meteorological phenomena and the behavior of the tracer in the investigated area. From the calculations it is concluded that the decrease in the $\mathrm{SF}_{6}$ concentrations in the Großes Tal resulted from flow splitting of the airflow into a side valley of the Großes Tal, up-slope winds and mountain venting over the mountain ridges, and mixed layer growth during the transport of the tracer from the entrance of the Großes Tal to the Schauinsland (Figure 5). The observed disturbance of the valley wind in the Großes Tal at midday was caused by the formation of a larger-scale westerly flow due to the formation of up-slope winds on the Black Forest slopes of the Rhine Valley. In the course of the morning, these winds reached the edge of the Black Forest slopes and penetrated farther eastward into the Black Forest. As a result of this penetration of the larger-scale westerly flow, the transport of air masses did no longer take place via the valley wind systems from Freiburg via the Zarten Basin and the Großes Tal to Schauinsland, but directly from the Rhine Valley over the Black Forest slopes to Schauinsland.

Volz-Thomas and Kolahgar [this issue] utilized the data obtained on June 5, 1996, for estimation of the average OH concentration during transport between Kappel and Schauinsland. With experimental information about the chemical composition of the background air from the airborne VOC measurements and the dilution factor from $\mathrm{SF}_{6}$, equation (3) was expanded using a simple mixing scheme:

$$
\ln \left(\frac{\left[\mathrm{RH}_{t}\right]_{s}}{f \times\left[\mathrm{RH}_{t}\right]_{K}+f^{\prime} \times\left[\mathrm{RH}_{t}\right]_{B}}\right)=-k_{1 i} \times[\overline{\mathrm{OH}}] \times \Delta t
$$

$\left[\mathrm{RH}_{i}\right]_{S},\left[\mathrm{RH}_{i}\right]_{K}$, and $\left[\mathrm{RH}_{t}\right]_{B}$ are the mixing ratios as measured at Schauinsland $\left(t_{2}\right)$, at Kappel $\left(t_{1}\right)$, and in the air above Kappel $\left(t_{1}\right) . \Delta t$ is the transport time between Kappel $\left(t_{1}\right)$ and Schauinsland $\left(t_{2}\right)$, and $f=0.1$ is the reciprocal dilution factor. Both quantities are obtained from the $\mathrm{SF}_{6}$ maxima at Kappel and Schauinsland (see above), and $f^{\prime}=(1-f)$ is the fraction at which the background air is admixed to the plume.

The resulting $\mathrm{OH}$ concentration of $7 \times 10^{6} \mathrm{~cm}^{-3}$ is $30 \%$ lower than that obtained without background correction, that is, using equation (3), still almost a factor of 2 larger than what is calculated with a chemical box model constraint by the measured trace gas concentrations and photolysis rates. The radi- 


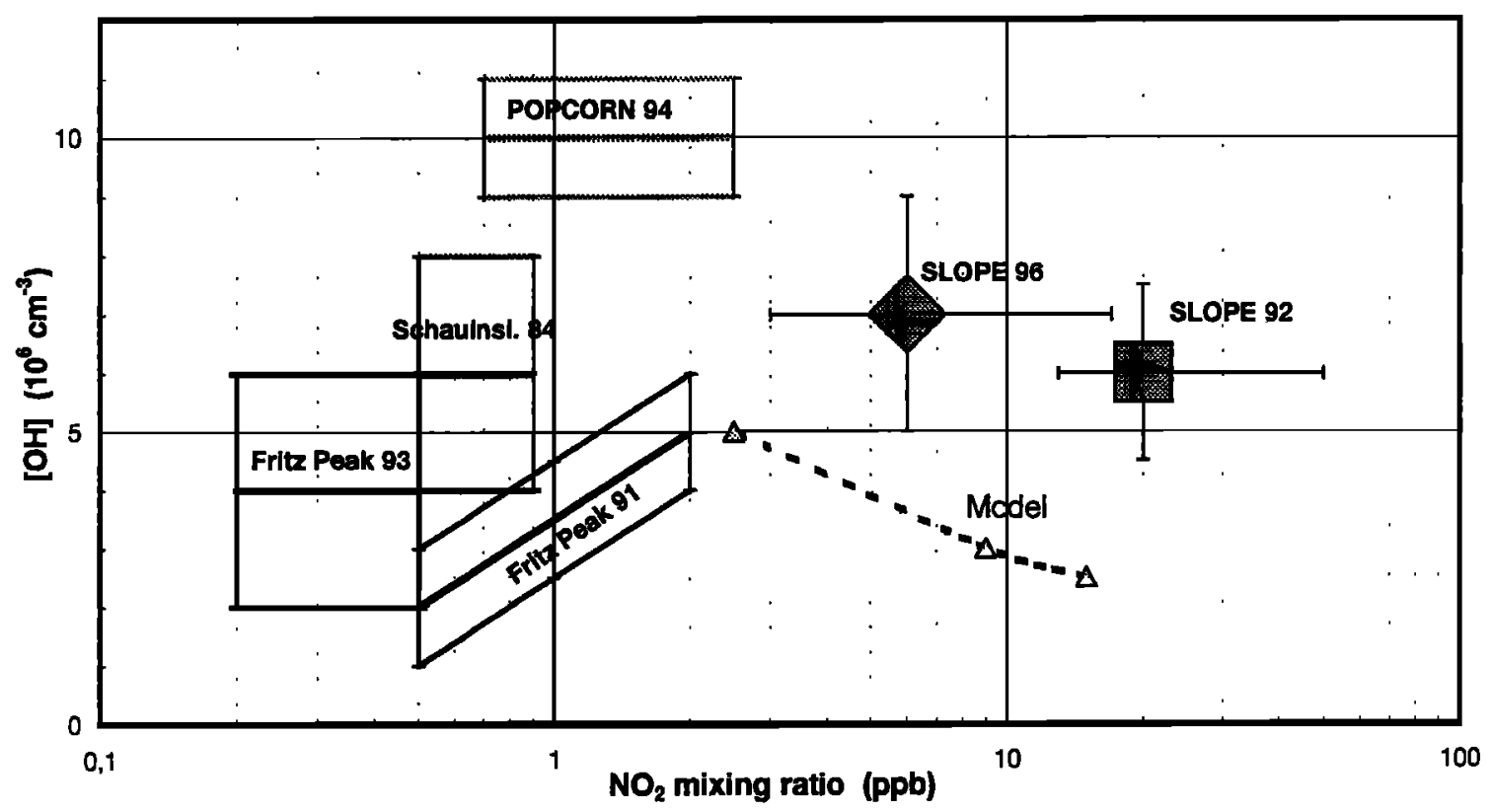

Figure 6. $\mathrm{OH}$ concentrations as measured at different locations with different techniques as a function of the prevailing $\mathrm{NO}_{2}$ mixing ratio (see Volz-Thomas and Kolahgar [this issue] for details).

cal budget can be closed within the experimental uncertainties, when an upper limit is adopted for the photolysis of nitrous acid, in addition to the radical production from photolysis of ozone, $\mathrm{H}_{2} \mathrm{O}_{2}$, and carbonyl compounds as well as ozonolysis of unsaturated VOCs. Biogenic VOCs contribute significantly to the recycling of $\mathrm{HO}_{x}$ and represent, on average, about $50 \%$ to the total VOC reactivity measured at the surface sites. The results from SLOPE96, in particular the analysis of the tracer experiment, confirm the assumptions made in the analysis of the earlier experiment conducted in 1992, when noontime $\mathrm{OH}$ concentrations of $(6-8) \times 10^{6} \mathrm{~cm}^{-3}$ were derived in the presence of $\mathrm{NO}_{x}$ mixing ratios between $70 \mathrm{ppb}$ at the entrance of the valley and $15 \mathrm{ppb}$ at Schauinsland.

A comparison of the results obtained from SLOPE with direct measurements from different studies is shown in Figure 6. As discussed by Volz-Thomas and Kolahgar [this issue], the data qualitatively exhibit the theoretically expected dependence of $[\mathrm{OH}]$ on the $\mathrm{NO}_{2}$ mixing ratio with a maximum around $1 \mathrm{ppb}$ of $\mathrm{NO}_{2}$, but seem to give larger $\mathrm{OH}$ concentrations in the high- $\mathrm{NO}_{x}$ regime than what is currently believed.

\section{Conclusions}

The valley Großes Tal between Freiburg and Schauinsland was used as an approximation of a chemical flow reactor in order to study chemistry and transport in the city plume of Freiburg. Transport and dispersion was quantified from a tracer experiment and detailed meteorological measurements, including vertical profiles at six different locations.

Relatively large concentrations of hydroxyl radicals are estimated from the decay of reactive hydrocarbons in the plume, which may point to as yet unknown processes. The radical budget can be closed, however, within the experimental uncertainties if sources of $\mathrm{HO}_{x}$ from the ozonolysis of alkenes and the photolysis of carbonyl compounds, $\mathrm{H}_{2} \mathrm{O}_{2}$, and HONO are included at their maximum rates allowed from the measurements or other estimates. Biogenic emissions seem to have a large influence on the total VOC reactivity in the valley, even at times when the city plume passes.

The tracer experiment and the interpretation of the meteorological data also allowed to confirm the validity of the assumptions made for the estimation of $[\mathrm{OH}]$ from the experiment in 1992. It seems therefore as if $\mathrm{OH}$ concentrations in the high- $\mathrm{NO}_{x}$ regime might indeed be substantially larger than what is currently assumed.

With appropriate nesting (from $5 \mathrm{~km}$ to $250 \mathrm{~m}$ grid spacing), the transport model KAMM is capable of describing the flow and dispersion of the tracer in the narrow valley, including the observed asymmetry perpendicular to the valley axis. The comprehensive data set collected during SLOPE96 provides a unique opportunity for the testing of chemical transport models. Future work will include modeling studies to investigate the potential causes for the large $\mathrm{OH}$ concentrations in the high- $\mathrm{NO}_{x}$ regime.

Acknowledgments. We would like to express our thanks to the numerous investigators and coworkers involved in SLOPE96 for their enthusiasm. Particular thanks are due to those who have actively contributed to the scientific interpretation and the publications in this special section. We gratefully acknowledge the support that was provided by the local authorities of the city of Freiburg and the village Kappel, the staff of the Umweltbundesamt at Schauinsland, and the inhabitants of the Großes Tal. Many thanks also to Gerhard Smiatek of the Fraunhofer Institut in Garmisch-Partenkirchen, who kindly provided us with data for the map in Figure 1, and to Sabine Jansen for her expert assistance in data handling and analysis. The work was supported by the German Research Minister (BMBF) as part of EUROTRAC (contract 07 EU 723/5A) and TFS (contract 07 TFS 31/ HA.3).

\section{References}

Allwine, K. J., Atmospheric dispersion and tracer ventilation in a deep mountain valley, J. Appl. Meteorol., 32, 1017-1037, 1993.

Atkinson, B. W., Meso-Scale Atmospheric Circulations, 495 pp., Academic, San Diego, Calif., 1981. 
Barry, R. G., Mountain Weather and Climate, 402 pp., Routledge, London, 1992.

Bischoff-Gauß, I., N. Kalthoff, and F. Fiedler, The impact of secondary flow systems on air pollution in the area of Sao Paulo, J. Appl. Meteorol., 37, 269-287, 1998.

Blake, N. J., S. A. Penkett, K. C. Clemitshaw, P. Anwyl, P. Lightman, A. R. W. Marsh, and G. Butcher, Estimate of atmospheric hydroxyl radical concentrations from the observed decay of many reactive hydrocarbons in well-defined urban plumes, J. Geophys. Res., 98, 2851-2864, 1993.

Calvert, J. G., Hydrocarbon involvement in photochemical smog formation in Los Angeles atmosphere, Environ. Sci. Technol., 10, 256$262,1976$.

Carroll, J. J., and R. L. Baskett, Dependence of air quality in a remote location on local and mesoscale transports: A case study, J. Appl. Meteorol., 18, 474-486, 1979.

Clements, W. E., J. A. Archuleta, and P. H. Gudiksen, Experimental design of the 1984 ASCOT field study, J. Appl. Meteorol., 28, 405$413,1989$.

Crutzen, P. J., The role of NO and $\mathrm{NO}_{2}$ in the chemistry of the troposphere and stratosphere, Ann. Rev. Earth Planet. Sci., 7, 443$472,1979$.

Dorn, H. P., J. Callies, U. Platt, and D. H. Ehhalt, Measurement of tropospheric $\mathrm{OH}$ concentrations by laser long-path absorption spectroscopy, Tellus, Ser. B, 40, 437-445, 1988.

Ehhalt, D. H., F. Rohrer, A. Wahner, M. J. Prather, and D. R. Blake, On the use of hydrocarbons for the determination of tropospheric OH concentrations, J. Geophys. Res., 103, 18,981-18,997, 1998.

Eisele, F. L., G. H. Mount, F. C. Fehsenfeld, J. Harder, E. Marovich, D. D. Parrish, J. R. Roberts, M. Trainer, and D. Tanner, Intercomparison of tropospheric $\mathrm{OH}$ and ancillary trace gas measurements at Fritz Peak Observatory, Colorado, J. Geophys. Res., 99, 18,605$18,626,1994$.

Fiedler, F., Development of meteorological computer models, Interdiscip. Scl. Rev., 18, 192-198, 1993.

Fiedler, F., Die Entstehung von bodennahem Ozon und Auftreten von Sommersmog, in Warnsıgnal Klıma, edited by J. L. Lozan, H. Graßl, and P. Hupfer, pp. 138-143, Auswertungen, Hamburg, Germany, 1998.

Fiedler, F., I. Bischoff-Gauß, N. Kalthoff, and G. Adrian, Modeling of transport and diffusion of a tracer in the Freiburg-Schauinsland area, $J$ Gcophys Res., this issue.

Harrison, R. M., J. D. Peak, and G. M. Collins, Tropospheric cycle of nitrous acid, J Geophys. Res., 101, 14,429-14,432, 1996.

Holland, F., U. Aschmutat, M. HeBling, A. Hofzumahaus, and D. H. Ehhalt, Highly time resolved measurements of $\mathrm{OH}$ during POPCORN using laser-induced fluorescence spectroscopy, J. Atmos. Chem., 31, 205-225, 1998.

Jang, J. C., H. E. Jeffries, and S. Tonnesen, Sensitıvity of ozone to model grid resolution, II, Detailed process analysis for ozone chemistry, Atmos. Environ., 29, 3101-3114, 1995.

Jeffries, H. E., and S. Tonessen, A comparison of two photochemical reaction mechanisms using mass balance and process analysis, $A t-$ mos. Environ., 28, 2991-3003, 1994.

Jobson, B. T., H. Niki, Y. Yokouchi, J. Bottenheim, F. Hopper, and R. Lealtsch, Measurements of $\mathrm{C}_{2}-\mathrm{C}_{6}$ hydrocarbons during the Polar Sunrise Experiment: Evidence for $\mathrm{Cl}$ atom and $\mathrm{Br}$ atom chemistry, J. Geophys. Res., 99, 25,355-25,368, 1994.

Kalthoff, N., V. Horlacher, U. Corsmeier, A. Volz-Thomas, B. Kolahgar, H. Geıss, M. Möllmann-Coers, and A. Knaps, Influence of valley winds on transport and dispersion of airborne pollutants in the Freiburg-Schauinsland area, J. Geophys. Res., this issue.

Kessler, C., and U. Platt, Nitrous acid in polluted air masses-Sources and formation pathways, paper presented at 3rd Symposium on Physico-Chemical Behavior of Atmospheric Pollutants, Comm. of the Eur. Communities, Varese, Italy, 1984.
Kley, D., J. Beck, P. I. Grennfelt, $\emptyset$. Hov, and S. A. Penkett, Tropospheric Ozone Research (TOR) - A sub-project of EUROTRAC, $J$. Atmos. Chem., 28, 1-9, 1997.

Kramp, F., and A. Volz-Thomas, On the budget of $\mathrm{OH}$ radicals and ozone in an urban plume from the decay of $\mathrm{C}_{5}-\mathrm{C}_{8}$ hydrocarbons and NO $_{x}$, J. Atmos. Chem., 28, 263-282, 1997.

Kurita, H., H. Ueda, and S. Mitsumoto, Combination of local wind systems under gradient wind conditions and its contribution to the long-range transport of air pollutants, J. Appl. Meteorol., 29, 331348,1990 .

Levy, H., Normal atmosphere: Large radical and formaldehyde concentrations predicted, Science, 173, 141, 1971.

Logan, J. A., M. J. Prather, S. C. Wofsy, and M. B. McElroy, Tropospheric chemistry: A global perspective, J. Geophys Res., 86, 72107254, 1981.

McKeen, S. A., and S. C. Liu, Hydrocarbon ratios and photochemical history of air masses, Geophys. Res. Lett., 20, 2363-2366, 1993.

McKenna, D. S., Analytic solutions of reaction diffusion equations and implications for the concept of an air parcel, J. Geophys. Res., 102, 13,719-13,725, 1997.

McKenna, D. S., C. J. Hord, and J. M. Kent, Hydroxyl radical concentrations and Kuwait oil fire emission rates for March 1991, J. Geophys. Res., 100, 26,005-26,025, 1995.

Millan, M., Begona Artinano, in Mesometeorological Cycles of Air Pollution in the Ibenan Peninsula, Air Pollut. Res. Rep. 44, 219 pp., Comm. of the Eur. Communities, Valencia, 1992.

Mount, G. H., and E. J. Williams, An overview of the Tropospheric OH Photochemistry Experiment, Fritz Peak/Idaho Hill, Colorado, fall 1993, J. Geophys. Res., 102, 6171-6186, 1997.

Pätz, H.-W., et al., Measurements of trace gases and photolysıs frequencies during SLOPE96 and a course estımate of the local $\mathrm{OH}$ concentration from $\mathrm{HNO}_{3}$ formation, J. Geophys. Res., this issue.

Roberts, J. M., F. C. Fehsenfeld, S. C. Liu, M. J. Bollinger, C. Hahn, D. L. Albritton, and R. E. Sievers, Measurements of aromatic hydrocarbon ratios and $\mathrm{NO}_{x}$ concentrations in the rural troposphere: Observation of air mass photochemical aging and $\mathrm{NO}_{x}$ removal, Atmos. Environ., 18, 2421-2432, 1984.

Satsumabayashi, H., H. Kurita, Y. Chang, G. R. Carmıchael, and H. Ueda, Diurnal variation of $\mathrm{OH}$ radical and hydrocarbons in a polluted air mass during long-range transport in central Japan, Atmos. Environ., 26, 2835-2844, 1992.

Volz-Thomas, A., and B. Kolahgar, On the budget of hydroxyl radicals at Schauinsland during SLOPE96, J. Geophys. Res., this issue.

Volz-Thomas, A., et al., Photo-oxidants and precursors at Schaunsland, Black Forest: Chemistry and transport, in Tropospheric Ozone Research, edited by $\emptyset$. Hov, pp. 323-332, Springer-Verlag, New York, 1997.

Whiteman, C. D., Observations of thermally developed wind systems in mountainous terrain, in Atmospheric Processes Over Complex Terrain, Meteorol. Monogr., vol. 23, edited by W. Blumen, pp. 5-42, Am. Meteorol. Soc., Boston, Mass., 1990.

Wilson, R., F. Shair, B. Reynolds, and W. Greene, Characterization of the transport and dispersion of pollutants in a narrow mountain valley region by means of an atmospheric tracer, Atmos. Environ., 17, 1633-1647, 1983.

H. Geiß and A. Volz-Thomas, Institut für Chemie und Dynamik der Geosphare II, Forschungszentrum Jülich, P.O. Box 1913, D-52425 Jülich, Germany. (a.volz-thomas@kfa-juelich.de)

N. Kalthoff, Institut für Meteorologie und Klimaforschung, Forschungszentrum Karlsruhe, P.O. Box 3640, D-76021 Karlsruhe, Germany.

(Received June 11, 1999; revised August 25, 1999; accepted August 30, 1999.) 